\title{
Non-neuronal cells are not the limiting factor for the low axonal regeneration in C57BL/6] mice
}

A.L.R. Oliveira ${ }^{1}$ and F. Langone ${ }^{2}$

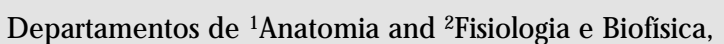

Universidade Estadual de Campinas, Campinas, SP, Brasil

\section{Correspondence}

A.L.R. O liveira

Departamento de Anatomia

Instituto de Biologia, UNICAMP

Caixa Postal 6109

13083-970 Campinas, SP

Brasil

Fax: +55-19-289-3124

E-mail: alroliv@ unicamp.br

Research supported by CNPq.

Publication supported by FAPESP.

Received April 3, 2000

Accepted August 14, 2000

\section{Abstract}

Peripheral axonal regeneration was investigated in adult male mice of the $\mathrm{C} 57 \mathrm{BL} / 6 \mathrm{~J}(\mathrm{C}), \mathrm{BALB} / \mathrm{cJ}(\mathrm{B})$ and $\mathrm{A} / \mathrm{J}(\mathrm{A})$ strains and in their $\mathrm{F} 1$ descendants using a predegenerated nerve transplantation model. Four types of transplants were performed: 1 ) isotransplants between animals of the $\mathrm{C}, \mathrm{B}$ and $\mathrm{A}$ strains; 2) donors of the $\mathrm{C}$ strain and recipients of the $\mathrm{C} \times \mathrm{B}$ and $\mathrm{C} \times \mathrm{A}$ breeding; 3) donors of the $\mathrm{B}$ strain and recipients of the $\mathrm{C} \times \mathrm{B}$ breeding, and 4) donors of the $\mathrm{A}$ strain and recipients of the $\mathrm{C} x \mathrm{~A}$ breeding. Donors had the left sciatic nerve transected and two weeks later a segment of the distal stump was transplanted into the recipient. Four weeks after transplantation the regenerated nerves were used to determine the total number of regenerated myelinated fibers (TMF), diameter of myelinated fibers (FD) and myelin thickness (MT). The highest TMF values were obtained in the groups where $\mathrm{C} 57 \mathrm{BL} / 6 \mathrm{~J}$ mice were the donors $(\mathrm{C}$ to $\mathrm{F} 1(\mathrm{C} \times \mathrm{B})=$ $4658 \pm 304 ; \mathrm{C}$ to $\mathrm{F} 1(\mathrm{C} \times \mathrm{A})=3899 \pm 198)$. Also, $\mathrm{A} / \mathrm{J}$ grafts led to a significantly higher TMF (A to F1 $(\mathrm{C} \times \mathrm{A})=3933 \pm 565)$. Additionally, isotransplant experiments showed that when the nerve is previously degenerated, C57BL/6J mice display the largest number of myelinated fibers ( $\mathrm{C}$ to $\mathrm{C}=3136 \pm 287$; $\mathrm{B}$ to $\mathrm{B}=2759 \pm 170$, and $\mathrm{A}$ to $\mathrm{A}=2835 \pm 239$ ). We also observed that when $\mathrm{C} 57 \mathrm{BL} / 6 \mathrm{~J}$ was the graft donor, FD was the highest and MT did not differ significantly when compared with the other groups. These morphometric results reinforce the idea that Schwann cells and the nerve environment of C57BL/6J provide enough support to the regenerative process. In this respect, the present results support the hypothesis that the non-neuronal cells, mainly Schwann cells, present in the sciatic nerve of $\mathrm{C} 57 \mathrm{BL} / 6 \mathrm{~J}$ mice are not the main limiting factor responsible for low axonal regeneration.

\section{Introduction}

After axotomy, a sequence of events occurs distally to the lesion, resulting in nerve degeneration (1-4). This process, called Wallerian degeneration, is initiated by a local inflammation when several signal mol-
- Nerve regeneration

- Schwann cells

- Isogenic mice

- Nerve transplantation

- Tubulization
Key words ecules such as cytokines are produced (5-7). As a result, there is a massive macrophage invasion, mainly into the microenvironment of the distal stump of the nerve, where they are responsible for myelin sheath and nerve fiber phagocytosis (8-11). Another essential cell type is the Schwann cell, which also 
participates in the myelin and axonal clearance. Finally, the Schwann cells will support and guide the regenerating axons to the target organs by lining themselves up, forming the bands of Büngner $(8,9,12,13)$. They also produce neurotrophic factors such as NGF, BDNF, NT-3, NT-4 and CNTF that support neuronal survival (14-18).

In the literature concerning nerve regeneration, the importance of non-neural cells, such as Schwann cells and macrophages, has been emphasized (19-23). Less attention has been given to the intrinsic regenerative neuronal characteristics, which are also an important limiting factor for the nerve regenerative process $(24,25)$. In this regard, neuronal survival after axotomy is a prerequisite for regeneration and is facilitated by various trophic factors (21). Also, axotomized neurons must switch from a transmitting mode to a growth mode, expressing growth-associated proteins, such as GAP-43, as well as different neuropeptides and cytokines (26). Axonal sprouts must reach the distal nerve stump at a time when its growth support is optimal $(27,28)$. If such coordination does not occur, nerve regeneration may be diminished and neuronal death may occur. In this respect, an interesting example is the $\mathrm{C} 57 \mathrm{BL} / 6 \mathrm{~J}$ mouse strain, which shows delayed axonal regeneration after a peripheral lesion (29-31).

Lu et al. $(29,30)$ observed that C57BL/6J mice have a lower axonal regeneration potential after a crush lesion compared with $\mathrm{BALB} / \mathrm{cJ}, \mathrm{A} / \mathrm{J}, \mathrm{C} 3 \mathrm{H} / \mathrm{HeJ}$ and DBA/1 J mice. These results were confirmed by Lainetti et al. (31) in a study of axonal regeneration in the same strains, using the nerve tubulization technique. They also observed that C57BL/ $6 \mathrm{~J}$ displays extensive dorsal root ganglion death after lesion.

The first hypothesis to explain the low axonal regeneration of $\mathrm{C} 57 \mathrm{BL} / 6 \mathrm{~J}$ mice was to relate it to its intrinsic deficiency in macrophage response to injury. Nevertheless, this was not experimentally confirmed (29). Also, Lu et al. (30) investigated the genetics of this deficiency in recombinant mouse strains, and proposed that it could be a result of a temporary deficiency rather than a permanent neuronal impairment, which seems to involve mainly sensitive neurons.

Based on the facts reported above, it is still not well understood if the regenerative deficiency of C57BL/6J mice is mainly a result of the intrinsic neuronal characteristics or if it is due to the nerve microenvironment and non-neural cell features. In the present study we propose an in vivo model based on predegenerated allo- and isograft transplants using the $\mathrm{C} 57 \mathrm{BL} / 6 \mathrm{~J}(\mathrm{C}), \mathrm{A} / \mathrm{J}(\mathrm{A})$, $\mathrm{BALB} / \mathrm{cJ}$ (B) strains, and their $\mathrm{F} 1$ descendants. This method was used in order to determine the relative importance of neuronal and non-neuronal $\mathrm{C} 57 \mathrm{BL} / 6 \mathrm{~J}$ cells in peripheral nerve regeneration after sciatic nerve transection.

\section{Material and Methods}

\section{Animals}

In this study, fifty-one 8 to 10 -week-old male mice were used. These mice were from C57BL/6J $(\mathrm{N}=15), \mathrm{BALB} / \mathrm{cJ}(\mathrm{N}=12), \mathrm{A} / \mathrm{J}$ $(\mathrm{N}=12)$ isogenic strains, and their $\mathrm{F} 1 \mathrm{de}-$ scendants: F1 (C57BL/6J x A/J) [F1 (C x A)] $(\mathrm{N}=6)$ and $(\mathrm{C} 57 \mathrm{BL} / 6 \mathrm{~J} \times \mathrm{BALB} / \mathrm{cJ})[\mathrm{F} 1(\mathrm{C} \times$ $\mathrm{B})](\mathrm{N}=6)$. Three additional male mice from C57BL/6J, A/J and BALB/cJ isogenic strains were used for the predegenerated nerve graft morphological study.

Two main groups were studied: the first was based on sciatic nerve allotransplants and $\mathrm{C} 57 \mathrm{BL} / 6 \mathrm{~J}$ mice were used as graft donor for both $\mathrm{F} 1(\mathrm{C} \times \mathrm{A})(\mathrm{N}=3)$ and $\mathrm{F} 1(\mathrm{C} \times \mathrm{B})(\mathrm{N}$ $=3)$. Also, $\mathrm{A} / \mathrm{J}$ and $\mathrm{BALB} / \mathrm{cJ}$ mice were used as donors for $\mathrm{F} 1(\mathrm{C} \times \mathrm{A})(\mathrm{N}=3)$ and $\mathrm{F} 1(\mathrm{C} \mathrm{x}$ B) $(\mathrm{N}=3)$, respectively.

The second main group was based on sciatic nerve isotransplants and, in this case, the donor and recipients were from the same strain: $\mathrm{C} 57 \mathrm{BL} / 6 \mathrm{~J}(\mathrm{~N}=6), \mathrm{A} / \mathrm{J}(\mathrm{N}=6)$ and $\mathrm{BALB} / \mathrm{cJ}(\mathrm{N}=6)$. 


\section{Surgical procedures (Figure 1)}

Under deep anesthesia (pentobarbital, 50 $\mathrm{mg} / \mathrm{kg}$, ip), donors received a left sciatic nerve transection at the obturator tendon level and the proximal stump was ligated to avoid regeneration. Two weeks later, the donor transected nerve was exposed and the distal stump was dissected out for transplantation. One millimeter of the proximal end of the predegenerated donor nerve was introduced and attached to a 3-mm long polyethylene tube. At the same time, the recipient's sciatic nerve was exposed and transected at the mid-thigh level and its proximal stump was inserted and sutured into the polyethylene tube containing the donor predegenerated nerve, with a 1-mm gap left between the stumps.

\section{Specimen preparation and morphologic and morphometric analysis}

Four weeks after transplantation, recipients were perfused transcardially with Karnovsky solution (2\% glutaraldehyde and $1 \%$ paraformaldehyde) and the regenerated sciatic nerves were dissected out. The specimens were post-fixed with $2 \%$ osmium tetroxide and processed for Araldite embedding. Transverse semithin sections $(0.5 \mu \mathrm{m}$ thick $)$ were obtained at the midpoint of the polyethylene tube and stained with toluidine blue and the total number of regenerated axons (TMF) was counted. Also, the TMF in the contralateral sciatic nerve (CL) was obtained and a regeneration rate ( $R R$ ) was calculated $(\mathrm{RR}=\mathrm{TMF} / \mathrm{CL})$. Transverse ultrathin sections were obtained and 4 fields of each specimen were photographed with the electron microscope $(2000 \mathrm{X})$ covering an area of at least $30 \%$ of the cross-sectional area of the nerve. Sampling bias was avoided by spreading the micrographs systematically over the entire cross-section according to the scheme proposed by Mayhew and Sharma (32). The negatives were copied (X3) and the diameter of myelinated fibers and myelin thickness were measured on a digitizing table (SummaSketch ${ }^{\circledR}$ II Professional) using Sigma Scan Measurement ${ }^{\circledR}$ software. Axon diameter (D) was calculated from the perimeter (P) by applying the formula $\mathrm{D}=\mathrm{P} / \pi$. Data are reported as means $\pm \mathrm{SD}$. One-way ANOVA and the Newman-Keuls test $(\mathrm{P}<0.05)$ were used for statistical analysis.

\section{Results}

\section{Morphological observations}

Predegenerated nerves (Figure 2). Two weeks after transection, predegenerated sciatic nerves from the three isogenic mice strains showed slight morphologic differences. The endoneural microenvironment was characterized by the presence of many groups of myelinated fibers undergoing Wallerian degeneration. These degenerating fibers showed accumulated mitochondria and membranous electron-dense bodies shrunk together with the disorganized myelin sheath in the Schwann cell cytoplasm. The Schwann cells were lined up into the so-called bands of Büngner, identified ultrastructurally by

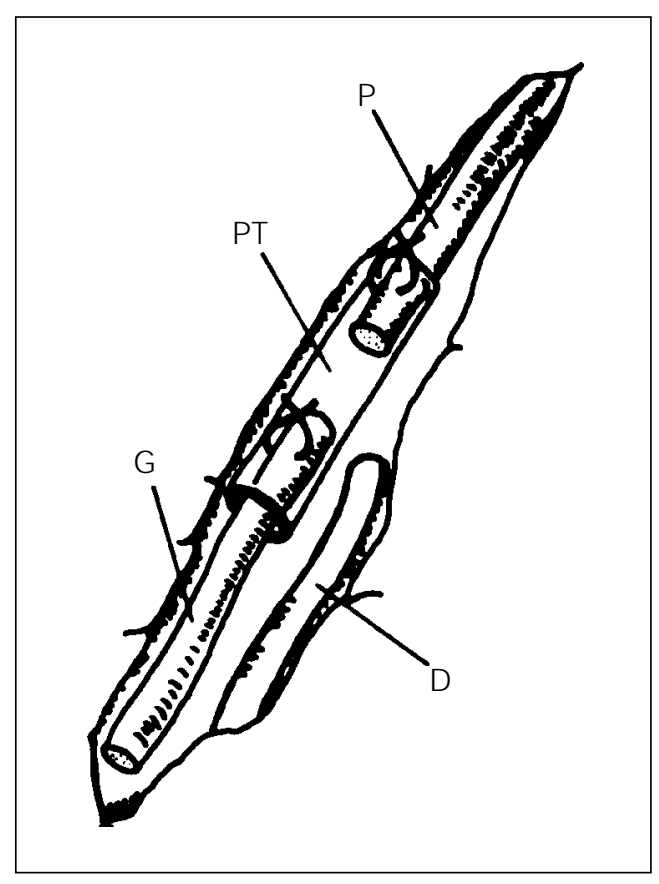

Figure 1 - Experimental model employed for the allo- and isotransplants. The proximal stump $(\mathrm{P})$ and the predegenerated graft (G) were inserted into a $3.0-\mathrm{mm}$ long polyethylene tube (PT) with a 1.0-mm gap left. The recipient distal stump (D) was left free. 
Figure 2 - A, Transverse section of a predegenerated nerve 2 weeks after sciatic nerve transection. The endoneural microenvironment is enlarged and there are many degenerating axons (DEG). A blood vessel is also observed (V). Bar $=10 \mu \mathrm{m}$. $B$, Electron microscopic transverse section of a sciatic nerve 2 weeks after transection. A macrophage (MAC) is observed degrading a myelinated fiber (AX) in the endoneural microenvironment. Also, many Schwann cell projections (arrowheads) surrounded by the basal lamina are observed between the endoneural collagen fibrils $(*)$. Bar $=1$ $\mu \mathrm{m}$. C, Detail of a Schwann cell (SC) with its cytoplasmic projections (arrowheads). The whole cell is surrounded by the basal lamina and endoneural collagen fibrils $(*)$. Bar $=1 \mu \mathrm{m}$. their characteristic basal lamina. Also macrophages were observed and distinguished from Schwann cells by their lack of basal lamina. These cells were usually associated with myelin debris and degenerating axons. The dimensions of the epineurium, perineurium and endoneurium were increased mainly due to cell proliferation and overproduction of extracellular matrix components such as collagen fibrils.

Regenerated nerves (Figures 3 and 4). Four weeks after lesion, a $1.5-\mathrm{mm}$ long tissue cable was observed surrounded by fluid in the center of the polyethylene tube, connecting the proximal stump and the previ-

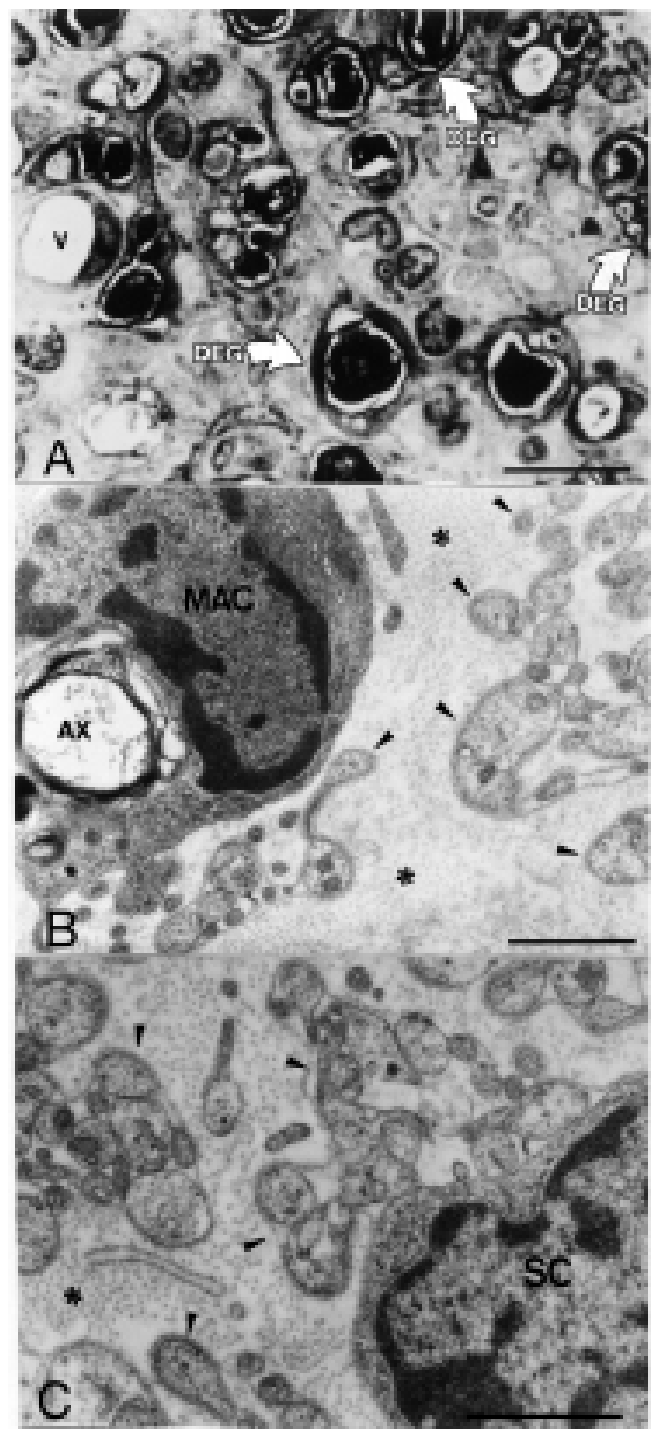

ously transplanted graft. Transverse semithin sections of the regenerated nerves at the tube midpoint showed regenerated myelinated fibers organized into small bundles surrounded by perineural-like cells and fibroblasts. Both isografts and allografts showed the same morphologic aspect when examined with the electron and light microscopes. The epineurium was composed of multiple layers of flattened cells separated by collagen fibrils. These cells resembled those of the bundles but did not have a basal lamina. The myelinated fibers were of different dimensions typically associated with just one Schwann cell, while the nonmyelinated axons were surrounded by several Schwann cell cytoplasmic projections. In the endoneural microenvironment we identified fibroblasts, macrophages and eventually mast cells. No immunological reaction resembling graft rejection was observed.

\section{Morphometric results}

Number of regenerated axons (Table 1, Figure 5). The TMF 4 weeks after graft transplantation surgery is shown in Table 1. The allotransplant group in which $\mathrm{C} 57 \mathrm{BL} / 6 \mathrm{~J}$ was the donor and $\mathrm{F} 1(\mathrm{C} \times \mathrm{B})$ the recipient showed the highest number of regenerated axons, followed by the groups in which $\mathrm{C} 57 \mathrm{BL} / 6 \mathrm{~J}$ and $\mathrm{A} / \mathrm{J}$ were donors $(\mathrm{P}<0.05$, Newman-Keuls test). On the other hand, when contralateral myelinated fiber numbers were computed for RR calculation, no statistical difference was observed between groups 1,2 and $3(\mathrm{P}>0.05$, Newman-Keuls test). The other groups did not differ concerning the number of regenerated axons.

\section{Axonal diameter and myelin thickness (Table 2)}

The diameters of myelinated fibers differed significantly between groups 4 weeks after graft transplantation $(\mathrm{P}<0.05$, NewmanKeuls test). When C57BL/6J was the allograft donor (groups 1 and 3), a significant- 

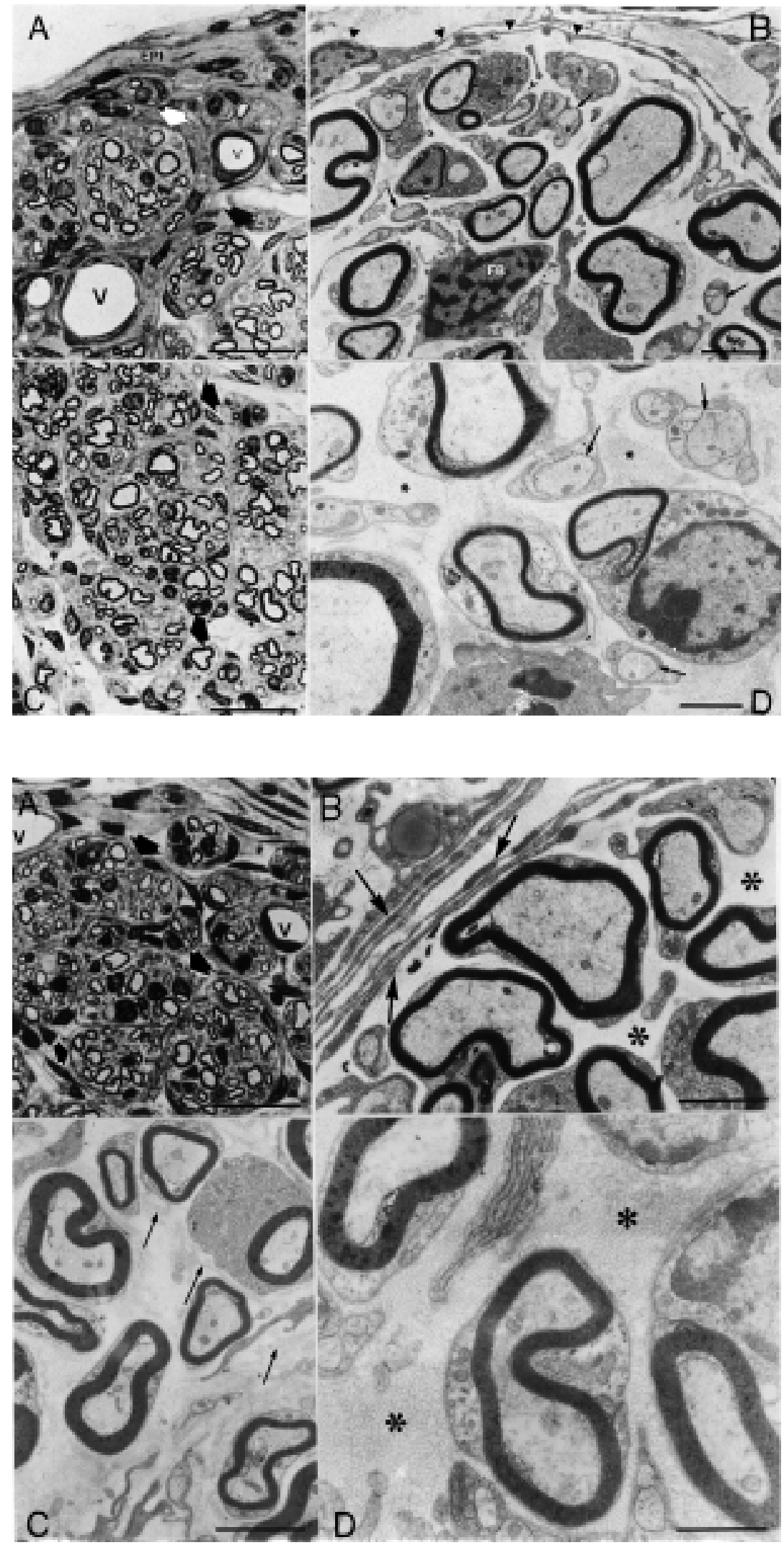

Figure 3 - A, Transverse semithin section of a regenerated nerve 4 weeks after graft transplantation. Donor: C57BL/6) , recipient: F1 (CXA). The epineurium (EPI) is composed of multiple layers of flattened cells and the regenerated nerve fibers are organized into small bundles (arrows). Blood vessels $(\mathrm{V})$ are also observed. Bar $=12.5 \mu \mathrm{m}$. B, Electron microscopic view of a regenerated nerve 4 weeks after graft transplantation. Donor: BALB/C) , recipient: F1 (C x B). Detail of a nerve bundle surrounded by perineural cells organized in concentric layers (arrowheads). Myelinated fibers, nonmyelinated fibers (arrows) and a fibroblast (FB) are observed in the endoneural microenvironment. Bar $=2$ $\mu \mathrm{m}$. C, Transverse semithin section of a regenerated nerve 4 weeks after graft transplantation. Donor: C57BL/6) , recipient: F1 (C x B). The axons are organized into bundles containing many regenerated nerve fibers (arrows). Bar $=12.5 \mu \mathrm{m}$. D, Electron microscopic view of a regenerated nerve 4 weeks after graft transplantation. Donor: C57BL/6], recipient: F1 (C x B). Detail of the endoneural microenvironment showing myelinated and nonmyelinated regenerated axons (arrows) associated with Schwann cells and surrounded by collagen fibrils $(*)$. Bar $=1 \mu \mathrm{m}$.
Figure 4 - A, Transverse section of a regenerated nerve 4 weeks after BALB/C] isograft transplantation. The regenerated fibers are distributed into fascicles bordered by circumferential projections of perineural cells (arrows). Blood vessels are also observed (V). Bar = $12.5 \mu \mathrm{m}$. B, Electron microscopic transverse section showing a BALB/CJ isograft bundle detail. The endoneurium contains collagen fibrils $(*)$ around the myelinated and nonmyelinated fibers. The perineural cells (arrows) are also observed surrounded by the basal lamina and containing mitochondria in their cytoplasmatic projections. Bar $=1 \mu \mathrm{m}$. C, Electron microscopic view of a regenerated nerve 4 weeks after C57BL/6] isograft transplantation. The endoneural microenvironment shows collagen fibrils and remaining empty basal lamina debris (arrows). The Schwann cells are associated with myelinated fibers, showing several mitochondria and a prominent rough endoplasmatic reticulum. Bar $=2 \mu \mathrm{m}$. D, Detail of a regenerated nerve bundle 4 weeks after $\mathrm{A} / \mathrm{J}$ isograft transplantation. The endoneurium is completely filled with collagen fibrils $\left(^{*}\right)$ surrounding the myelinated and nonmyelinated fibers which are associated with Schwann cells. Bar $=1 \mu \mathrm{m}$. 
Table 1 - Total number of regenerated axons (TMF) obtained at the polyethylene tube midpoint level 4 weeks after graft transplantation.

The number of myelinated fibers counted in the contralateral nerve $(C L)$ and the regeneration rate (RR) are also presented. 1) Donor: $C 57 \mathrm{BL} / 6 \mathrm{~J}(\mathrm{C})$, recipient: $\mathrm{F1}(\mathrm{C} \times \mathrm{A})$; 2) donor: $A / J(A)$, recipient: $F 1(C \times A)$; 3) donor: $C 57 B L / 6$, recipient: $F 1(C \times B)$; 4$)$ donor: BALB/CJ (B), recipient: $F 1$ (C x B); 5) donor: C57BL/6J , recipient: $C 57 B L / 6$; ; 6) donor: $A /$ J, recipient: $A / J$; 7) donor: $B A L B / C$, recipient: $B A L B / C$ J . The values are reported as means $\pm S D$. The capital letters indicate the comparison between the means of the 7 experimental groups, and the small letters show the comparison between each experimental group and its normal group. Different paired letters indicate statistical difference ( $P<0.05$, Newmann-Keuls test). $N=3$ for all groups.

\begin{tabular}{lccc}
\hline Group & TMF & $\mathrm{CL}$ & $\mathrm{RR}$ \\
\hline 1 & $3899.00 \pm 198.09 \mathrm{Aa}$ & $4135.67 \pm 104.00 \mathrm{~d}$ & $0.9435 \pm 0.061 \mathrm{~A}$ \\
2 & $3933.33 \pm 565.35 \mathrm{Aa}$ & $4052.33 \pm 53.27 \mathrm{~d}$ & $0.9857 \pm 0.167 \mathrm{~A}$ \\
3 & $4658.33 \pm 304.07 \mathrm{Bb}$ & $4314.47 \pm 97.67 \mathrm{e}$ & $1.0791 \pm 0.049 \mathrm{~A}$ \\
4 & $2595.00 \pm 30.35 \mathrm{CC}$ & $4327.33 \pm 46.48 \mathrm{e}$ & $0.5997 \pm 0.007 \mathrm{~B}$ \\
5 & $3136.00 \pm 287.00 \mathrm{CC}$ & $4120.67 \pm 72.57 \mathrm{~d}$ & $0.7615 \pm 0.075 \mathrm{~B}$ \\
6 & $2834.67 \pm 239.07 \mathrm{CC}$ & $4035.00 \pm 74.67 \mathrm{~d}$ & $0.7034 \pm 0.072 \mathrm{~B}$ \\
7 & $2759.00 \pm 169.52 \mathrm{CC}$ & $4250.00 \pm 68.56 \mathrm{~d}$ & $0.6496 \pm 0.048 \mathrm{~B}$
\end{tabular}

Table 2 - Fiber diameter (FD) and myelin thickness (MT) obtained at the polyethylene tube midpoint 4 weeks after graft transplantation.

Both values obtained for the regenerated and contralateral nerves are presented. 1) Donor: C57BL/6J (C), recipient: $F 1(C \times A) ; 2)$ donor: $A / J(A)$, recipient: $F 1(C \times A) ; 3)$ donor: C57BL/6J , recipient: $F 1(C \times B)$; 4) donor: $B A L B / C J(B)$, recipient: $F 1(C \times B) ; 5)$ donor: $C 57 \mathrm{BL} / 6 \mathrm{~J}$, recipient: $\mathrm{C} 57 \mathrm{BL} / 6 \mathrm{~J} ;$; 6) donor: $\mathrm{A} / \mathrm{J}$, recipient: $\mathrm{A} / \mathrm{J}$; 7) donor: $\mathrm{BALB} / \mathrm{C}$, recipient: $B A L B / C$ J . The values are reported as means $\pm S D$. The capital letters indicate the comparison between the means of the 7 experimental groups, and the small letters show the comparison between each experimental group and its normal group. Different paired letters indicate statistical difference $(P<0.05$, Newmann-Keuls test). N $=3$ for all groups.

\begin{tabular}{lccccc}
\hline \multirow{2}{*}{ Group } & \multicolumn{2}{c}{ FD } & & \multicolumn{2}{c}{ MT } \\
\cline { 2 - 3 } \cline { 5 - 6 } & Regenerated & Contralateral & & Regenerated & Contralateral \\
\hline 1 & $2.30 \pm 0.88 \mathrm{Aa}$ & $3.21 \pm 1.21 \mathrm{c}$ & & $0.29 \pm 0.10 \mathrm{Aa}$ & $0.66 \pm 0.25 \mathrm{~b}$ \\
2 & $2.09 \pm 0.86 \mathrm{Bb}$ & $3.21 \pm 1.21 \mathrm{c}$ & $0.30 \pm 0.09 \mathrm{Aa}$ & $0.66 \pm 0.25 \mathrm{~b}$ \\
3 & $2.24 \pm 0.92 \mathrm{Aa}$ & $3.65 \pm 1.60 \mathrm{~d}$ & $0.29 \pm 0.09 \mathrm{Aa}$ & $0.72 \pm 0.30 \mathrm{c}$ \\
4 & $2.05 \pm 0.86 \mathrm{Bb}$ & $3.65 \pm 1.60 \mathrm{~d}$ & $0.31 \pm 0.09 \mathrm{Aa}$ & $0.72 \pm 0.30 \mathrm{c}$ \\
5 & $1.98 \pm 0.86 \mathrm{Bb}$ & $3.55 \pm 1.61 \mathrm{~d}$ & $0.31 \pm 0.10 \mathrm{Aa}$ & $0.70 \pm 0.29 \mathrm{c}$ \\
6 & $2.00 \pm 0.76 \mathrm{Bb}$ & $3.27 \pm 1.30 \mathrm{c}$ & & $0.30 \pm 0.08 \mathrm{Aa}$ & $0.68 \pm 0.29 \mathrm{~b}$ \\
7 & $1.87 \pm 0.81 \mathrm{Bb}$ & $3.27 \pm 1.45 \mathrm{c}$ & $0.30 \pm 0.08 \mathrm{Aa}$ & $0.67 \pm 0.26 \mathrm{~b}$
\end{tabular}

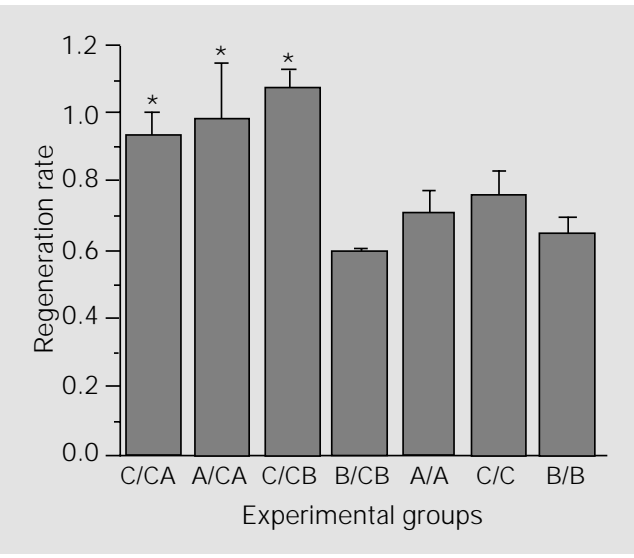

Figure 5 - Regeneration rate obtained by the division of total number of axons in the regenerated nerves by the number in the contralateral nerves. Experimental groups: $C / C A$ - donor: $C 57 B L / 6)$, recipient: $F 1(C \times A)$; $A / C A$ - donor: $A /$, recipient: $F 1(C \times A)$; $C / C B$ - donor: C57BL/6] , recipient: $\mathrm{F} 1$ (C $\times B)$; B/CB - donor: BALB/CJ recipient: $\mathrm{F} 1(\mathrm{C} \times \mathrm{B}) ; \mathrm{C} / \mathrm{C}$ - donor: $\mathrm{C} 57 \mathrm{BL} / 6 \mathrm{~J}$, recipient: C57BL/6J ; $A / A$ - donor: $A / J$, recipient: $A / J$; $B / B$ - donor: $B A L B / C$, recipient: $B A L B / C$ J . $* P<0.05$ compared to the other groups (Newman-Keuls test).

ly larger axonal diameter was observed $(\mathrm{P}<0.05)$. The other experimental groups did not differ significantly from one another. In all groups, axonal diameter was significantly smaller than control. Myelin thickness did not differ between the experimental groups but was always smaller than control $(\mathrm{P}<0.05)$.

\section{Discussion}

It has been shown that, following sciatic nerve crush, C57BL/6J mice have reduced axonal regeneration compared to other isogenic strains $(\mathrm{A} / \mathrm{J}, \mathrm{DBA} / 1 \mathrm{~J}, \mathrm{BALB} / \mathrm{cJ}$ and $\mathrm{C} 3 \mathrm{H} / \mathrm{HeJ})(29,30)$. Although the nature of the diminished regenerative potential has been studied by different methods, including breeding and nerve tubulization, it is still not completely understood. Possibly, both microenvironmental and neuronal characteristics are of importance during the initial steps of axonal sprouting and regeneration (33). Since in the nerve microenvironment macro- 
phage migration and activity in C57BL/6J was demonstrated not to be statistically different from the other strains, there is the possibility that Schwann cells may be involved. In this regard, several studies have emphasized the contribution of Schwann cells to the degenerative and regenerative processes after peripheral nerve injury $(9,10,22)$.

One way to investigate this hypothesis would be to transplant segments from a peripheral nerve of $\mathrm{C} 57 \mathrm{BL} / 6 \mathrm{~J}$ mice to recipients from another strain with a higher regenerative potential. Nevertheless, the direct allotransplant between strains would result in graft rejection since they have a different major histocompatibility complex (34). Considering this fact, in the present study we have proposed the utilization of $\mathrm{F} 1$ mice obtained by breeding C57BL/ 6 with $\mathrm{A} / \mathrm{J}$ and $\mathrm{BALB} / \mathrm{cJ}$ as graft recipients. Also, in order to have a higher number of Schwann cells in the graft already organized into the bands of Büngner, we have performed predegeneration of the donor nerves by transecting them two weeks before transplantation $(5,6,35$ 37). The morphologic results obtained two weeks after transplantation showed no rejection of the nerve grafts, since immunocompetent cells were almost absent.

Myelin thickness did not differ between experimental groups. Also, axonal diameter was significantly wider in the allotransplant groups where the $\mathrm{C} 57 \mathrm{BL} / 6 \mathrm{~J}$ strain was the donor. These facts demonstrate that C57BL/ 6J Schwann cells do not differ in myelin synthesis compared to those from the $\mathrm{A} / \mathrm{J}$ and $\mathrm{BALB} / \mathrm{cJ}$ strains. Also, the C57BL/6J nerve microenvironment is able to support axonal regeneration.

The TMF was higher in the allotransplant groups where the $\mathrm{C} 57 \mathrm{BL} / 6 \mathrm{~J}$ and $\mathrm{A} / \mathrm{J}$ strains were donors. Additionally, the group in which C57BL/6J mice were donors and F1 (C x B) mice were the recipients showed the highest TMF. Since the TMF counted for the contralateral nerves was not even for all groups (Table 1), we calculated the ratio between the ipsilateral and contralateral sides (RR). In this regard, no statistical RR differences were found between $\mathrm{F} 1$ recipients that received $\mathrm{C} 57 \mathrm{BL} / 6 \mathrm{~J}$ or $\mathrm{A} / \mathrm{J}$ grafts. This ratio was higher than observed in F1 recipients, which received BALB/cJ grafts.

These results reinforce the hypothesis that the nerve microenvironment of C57BL/ $6 \mathrm{~J}$ mice does provide support to axonal regeneration. Nevertheless, the low axonal regeneration previously reported indicated a substantial sensory neuron death, a fact that would contribute to establishing a permanent deficit (31). It is possible that the described neuronal death after sciatic nerve transection is the result of a mismatch in the timing of the neurons needed for neurotrophic substances and its production by the cells in the distal stump. The predegeneration of the graft used in our model may compensate for such delay, explaining the higher number of regenerated axons in the groups where C57BL/6J mice were donors.

Interestingly, basically using a similar transplantation model in Trembler mice, Pollard and McLeod (38) have demonstrated that the Schwann cells were responsible for the demyelinating neuropathy of this strain $(39,40)$. Based on the facts reported above, we believe that the experimental model used in our study would be able to show eventual Schwann cell abnormalities, which could be morphologically and morphometrically observed. In this respect, such cells and the nerve microenvironment are probably not the main factor contributing to the low axonal regeneration of $\mathrm{C} 57 \mathrm{BL} / 6 \mathrm{~J}$ mice.

Complementing the allograft experiment, we also performed isograft transplantations using $\mathrm{C} 57 \mathrm{BL} / 6 \mathrm{~J}, \mathrm{~A} / \mathrm{J}$ and BALB/cJ mice. In this particular experiment, we investigated the regeneration capacity of $\mathrm{C} 57 \mathrm{BL} / 6 \mathrm{~J}$ mice when the graft microenvironment is already undergoing Wallerian degeneration. Under these conditions, the counting and morphometric results showed no statistical differences between the three strains. Based on 
these data, it is possible that the non-neuronal cell response to injury is delayed in C57BL/6J mice. Such delay was reduced because of the isograft predegeneration, allowing early Wallerian degeneration steps to occur already before transplantation. On the other hand, soon after injury, the capacity of C57BL/6J neurons to recognize extracellular stimuli may be impaired, resulting in an initial delay in axonal regeneration. In this respect, apoptotic mechanisms may be involved that might contribute to explaining the previously described dorsal root ganglion death after sciatic nerve transection (Oliveira ALR, unpublished results).

\section{Acknowledgments}

We are grateful to Prof. Dr. Mary Anne $H$. Dolder for a careful review of the English text, and to Mr. Marco Aurélio and Mr. Norivaldo Celestino for excellent technical assistance.

\section{References}

1. Lunn ER, Brown MC \& Perry VH (1990). The pattern of axonal degeneration in the peripheral nervous system varies with different types of injury. J ournal of Neuroscience, 35: 157-165.

2. Cabaud HE, Rodkey WG \& Nemth TJ (1982). Progressive ultrastructural changes after peripheral nerve transection and repair. J ournal of Hand Surgery, 7: 353-365.

3. O'Daly J A \& Imaeda T (1967). Electron microscopy study of Wallerian degeneration in cutaneous nerves caused by mechanical injury. J ournal of Neuropathology and Experimental Neurology, 17: 744-766.

4. Thomas PK (1964). Changes in the endoneurial sheaths of peripheral myelinated nerve fibers during Wallerian degeneration. J ournal of Anatomy, 98: 175-182.

5. Bruck W, Bruck C, Marushak B \& Fried RL (1995). Mechanisms of macrophage recruitment in Wallerian degeneration. Acta Neuropathologica, 89: 363-367.

6. Hall SM (1993). Observations on the progress of Wallerian degeneration in transected peripheral nerves of C57BL/ Wld mice in the presence of recruited macrophages. J ournal of Neurocytology, 22: $480-490$.

7. Taskinen HS, Olsson T, Bucht A, Khademi M, Svelander L \& Royotta M (2000). Peripheral nerve injury induces endoneural expression of IFN-gamma, IL-10 and TNFalpha mRNA. J ournal of Neuroimmunology, 102: 17-25.

8. Stoll G, Griffin JW, Li CY \& Trapp BD (1989). Wallerian degeneration in the peripheral nervous system: participation of both Schwann cells and macrophages in myelin degradation. J ournal of Neurocytology, 18: 671-683.
9. Beuche W \& Fried RL (1984). The role of non-resident cells in Wallerian degeneration. J ournal of Neurocytology, 13: 767796.

10. Gibson J D (1979). The origin of the neural macrophage: a quantitative ultrastructural study of cell population changes during Wallerian degeneration. J ournal of Anatomy, 129: 1-19.

11. Monaco S, Gehrmann J, Raivich G \& Kreutzberg GW (1992). MHC-positive, ramified macrophages in the normal and injured rat peripheral nervous system. J ournal of Neurocytology, 21: 623-634.

12. Abernethy DA, Thomas PK, Rud A \& King RHM (1994). Mutual attraction between emigrant cells from transected denervated nerve. Journal of Anatomy, 184: 239-249.

13. Son YJ \& Thompson WJ (1995). Schwann cell processes guide regeneration of peripheral axons. Neuron, 14: 125-132.

14. Funakoshi H, Frisen J, Barabany G, Timmusk T, Zachrisson O, Verge VMK \& Persson H (1993). Expression of mRNAs for neurotrophins and their receptors after axotomy of the sciatic nerve. J ournal of Cell Biology, 123: 455-464.

15. Lindsay RM (1994). Neurotrophins and receptors. Progress in Brain Research, 103: 3-14.

16. Millet FD (1994). Nerve growth factor and neuronal gene expression. Progress in Brain Research, 103: 23-34.

17. Sendtner $M$, Stockli $K A \&$ Thoenen $H$ (1992). Synthesis and localization of ciliary neurotrophic factor in the sciatic nerve of the adult rat after lesion during regeneration. J oumal of Cell Biology, 118: 139148.
18. Meyer M, Matsuoka I, Wetmore $\mathrm{C}$, Olson L \& Thoenen H (1992). Enhanced synthesis of brain-derived neurotrophic factor in the lesioned peripheral nerve: different mechanisms are responsible for the regulation of BDNF and NGF mRNA. J oumal of Cell Biology, 119: 45-54.

19. Dahlin LB (1995). Prevention of macrophage invasion impairs regeneration in nerve grafts. Brain Research, 679: 274280.

20. Madison RD \& Archibald SJ (1994). Point sources of Schwann cells result in growth into a nerve entubulation repair site in the absence of axons: effects of freeze-thawing. Experimental Neurology, 128: 266275.

21. Frostick SP, Yin Q \& Kemp GJ (1998) Schwann cells, neurotrophic factors, and peripheral nerve regeneration. Microsurgery, 18: 397-405.

22. Midha R, Mackinnon SE \& Becker LE (1994). The fate of Schwann cells in peripheral nerve allografts. J ournal of Neuropathology and Experimental Neurology, 53: 316-322.

23. Hall S (1986). The effect of inhibiting Schwann cell mitosis on the re-innervation of acellular autografts in the peripheral nervous system of the mouse. Neuropathology and Applied Neurobiology, 12: 401-414.

24. Fawcett J W (1992). Intrinsic neuronal determinants of regeneration. Trends in Neurosciences, 15: 5-8.

25. Fawcett J W \& Keynes RJ (1990). Peripheral nerve regeneration. Annual Review of Neuroscience, 13: 43-60.

26. Fu SY \& Gordon T (1997). The cellular and molecular basis of peripheral nerve re- 
generation. Molecular Neurobiology, 14: 67-116.

27. Donat J \& Wisniewsky HM (1973). The spatio temporal pattern of Wallerian degeneration in mammalian peripheral nerves. Brain Research, 53: 41-53.

28. Taira E, Takaha N \& Miki N (1993). Extracellular matrix proteins with neurite promoting activity and their receptors. Neuroscience Research, 17: 1-8.

29. Lu X, Richardson PM, Gervais F \& Skaeme E (1990). A deficiency of axonal regeneration in C57BL/6J mice. Brain Research, 510: 144-146.

30. Lu X, Skaeme E \& Richardson PM (1994). Studies of axonal regeneration in C57BL/ 6] and A/J mice. Brain Research, 652: 174-176.

31. Lainetti RD, Pereira FC \& Da-Silva CF (1995). Reduced sensory neuron regeneration by C57BL/6J mice. Brazilian J ournal of Medical and Biological Research,
28: 781-785.

32. Mayhew TM \& Sharma AK (1984). Sampling schemes for estimating nerve fibre size. II. Methods for unifascicular nerve trunks. J ournal of Anatomy, 139: 59-66.

33. Goldberg DJ \& Wu DY (1994). Regulation of events within the growth cone by extracellular clues: tyrosine phosphorylation. Progress in Brain Research, 103: 75-84.

34. Evans PJ, Midha R \& Mackinnon SE (1994). The peripheral nerve allograft: a comprehensive review of regeneration and neuroimmunology. Progress in Neurobiology, 43: 187-233.

35. Danielsen N \& Kerns J M (1994). Pre-degenerated nerve grafts enhance regeneration by shortening the initial delay period. Brain Research, 666: 250-254.

36. Kerns J M, Danielsen N, Holquist B, Kanje $M \&$ Lundborg G (1993). The influence of pre-degeneration on regeneration through nerve grafts in rats. Experimental Neurol- ogy, 122: 28-36.

37. Bryan DJ, Wang KK \& Summehayes IC (1999). Migration of Schwann cells in peripheral nerve regeneration. J ournal of Reconstructive Microsurgery, 15: 591596.

38. Pollard J D \& McLeod J G (1980). Nerve grafts in the Trembler mouse. An electrophysiological and histological study. J ournal of the Neurological Sciences, 46: 373383.

39. Heape AM, Bessoule JJ , Boiron-Sargueil F, Garbay B \& Cassagne C (1995). Sphingolipid metabolic disorders in Trembler mouse peripheral nerves in vivo result from an abnormal substrate supply. J ournal of Neurochemistry, 65: 1665-1673.

40. Sutter $U$, Welcher AA, Ozcelik T \& Snipes GJ (1992). Trembler mouse carries a point mutation in a myelin gene. Nature, 356: 241-244. 